\title{
Recommendations About Improvement of Application of Customs Procedure of Customs Transit in the Russian Federation When Transporting Goods by the Motor Transport
}

\author{
Olga A. Dmitrieva \\ Russian University of Transport (RUT - MIIT) \\ Moscow, Russia \\ E-mail: davis6589@mail.ru \\ Dmitry E. Morkovkin \\ Russian University of Transport (RUT - MIIT) \\ Moscow, Russia \\ E-mail: MorkovkinDE@mail.ru \\ Alla V. Pavlova \\ Russian University of Transport (RUT - MIIT) \\ Moscow, Russia \\ E-mail: alpav71@mail.ru
}

\author{
Elena N. Rudakova \\ Russian University of Transport (RUT - MIIT) \\ Moscow, Russia \\ E-mail: elena_nikolaevna_rf@mail.ru \\ Alexey V. Gubin \\ Russian University of Transport (RUT - MIIT) \\ Moscow, Russia \\ E-mail: avgubin@yandex.ru \\ Anton E. Polyakov \\ Russian University of Transport (RUT - MIIT) \\ Moscow, Russia \\ E-mail: polyakoff.miit@gmail.com
}

\begin{abstract}
In the conditions of the development of a market economy, customs regulation is a state instrument for carrying out foreign economic activity, on whose work depends the development of priority areas of the economy and entrepreneurship, including small and medium-sized businesses. Transport service represents the system of the technical, technological, economic, legal and organizational elements, which are in interrelation. Technical elements are characterized by accounting of physical and chemical properties of goods and operational parameters of vehicles. Technological elements of transport service are direct to improvement of quality of transport service with cost minimization. Economic elements consist in methods of state regulation of foreign economic activity. Legal elements represent the international contracts and agreements in the sphere of use of vehicles. Organizational elements of transport service consist in information support of transport processes of foreign economic activity. Transport service of foreign economic activity is carried out by means of use of certain modes of transport. It should be noted that concrete mode of transport affects the nature of transport service, which is defined by expediency and efficiency. The feature of the motor transport consists that it is one of widely used and allows delivering goods according to the scheme "from door to door", that is from initial to terminal point without implementation of overloads.
\end{abstract}

Keywords-economy; transport; customs authorities; customs transit; customs operations; Eurasian Economic Union

\section{INTRODUCTION}

The improvement of customs technologies and customs infrastructure of the EEU countries can play a significant role in the expansion of geography and the formation of optimal transportation patterns. The development of multimodal transportation can be support by further improvement of the regulatory framework and competent application of existing legal norms, in particular, when interpreting them in modern information and legal systems and information systems that implement customs operations

The transit opportunities of both the region and the country as a whole are determine by the current rules of the game, i.e. legislative and regulatory acts. Moreover, for the legislative base of transit operations, harmonization with international standards is very important, and it should be borne in mind that Russia is a member of the Eurasian Economic Union (hereinafter - the EEU).

One of the main issues of customs administration is customs transit and the problems arising from its use, ways to improve it, and, accordingly, the development of the transit potential of the entire EEU. The quality indicator of the transit system can be considered as a high degree of guarantee of delivery of goods to the destination, despite the fact that the guarantee system itself is not burdensome for carriers [4], [20]. [1], [2], [3]. 
The direction of further development of transit depends not only on the legal activities of the Federal Customs Service of Russia, but also on the positions of the EEU member states. It depends on which option is most acceptable and will create favorable conditions for the implementation of transit traffic on the territory of the EEU. Regulatory consolidation of the results of such development is possible within the framework of either the modernization of the existing customs legislation, or by joining international agreements already in force, which implies that the Federal Customs Service (hereinafter FCS) of Russia works together with the business community and develop a unified and coordinated position.

\section{STUDY METHODOLOGY}

The purpose of the publication is to analyze the scientific literature, regulatory framework and the results of research on customs procedures for customs transit in the Russian Federation during the transport of goods by road to determine ways of information interaction of customs authorities in monitoring transit traffic through the Eurasian Economic Union. The study used the following methods: a systematic approach, an integrated approach, comparative analysis, analysis of official statistics, and document analysis method.

In this article, the author has made attempt to reflect problems and recommendations about improvement of application of customs procedure of customs transit in the Russian Federation when transporting goods by the motor transport. In addition, has described prerequisites of introduction of the uniform computerized transit system (UCTS), in view of the international experience and experience of integration association, such as Eurasian Economic Union. The author has analyzed foreign experience of application of the procedure of customs transit taking into account the automated systems.

The scale and complexity of the tasks of introducing new information technologies require clarification of the principles and mechanism of their implementation based on a systematic approach to solving the problems of informatization of customs authorities, managing the development processes, equipping and implementing automated information systems.

\section{ASSESSMENT AND RESULTS}

Recognizing the importance and relevance of the customs procedure of customs transit (hereinafter - CPCT), the Federal Customs Service of Russia faces the task of modernizing the mechanism of customs control and regulation of the transit of goods, ensuring the reliability of control that meets the requirements for its simplicity, transparency and flexibility of application.

On December 16, 1994, in order to improve the technology of control over the delivery of goods under customs control and organization of information exchange between the customs authorities, an order was issue by the SCC of Russia No. 667 "On the creation of an automated control system for the delivery of goods under customs control (ACS DGS)".

Particular attention in the development of the system paid to information security. For the first time in the practice of the customs service when transmitting information, an electronic digital signature introduced confirming the authenticity of electronic messages, and encryption of the transmitted information applied.

The introduction of this system made it possible to raise control over compliance with the customs legislation of the Russian Federation to a qualitatively new level, promptly identify its violators and take effective measures against them, minimize the time between the commission of a customs offense and the moment of its detection.

AC TCS is effectively integrated with other automated systems. Examples that demonstrate the possibility of sharing information resources are the organization between the tax authorities of the European Union member countries and the Russian Federal Customs Service of information exchange on beef and pork imported into the Russian Federation by road from the EU as "sensitive goods", falling under the risk category, as well as inter-agency informational interaction with the Main Computing Center of the Russian Railways OJSC on the search for undelivered goods.

The use of "Automated Customs Transit Control System" contributes to reducing the volume of "paper" operations while exercising control over customs transit, improving the quality of filling in customs documents, and increasing the efficiency of information exchange.

The need for the introduction, improvement and application of new information technologies in the activities of the customs authorities of the Russian Federation is enshrined in paragraph 8 of Article 11 of Chapter 2 of the Federal Law "On Customs Regulation in the Russian Federation" No. 311-Ф3 dated November 27, 2010.

Therefore, in solving the problems posed, the experience of foreign states and associations will be useful, as well as the experience in the field of customs transit that has accumulated in the EEU member states.

The essence of the approach will be to create a unified computerized transit system (hereinafter referred to as UCTS) of the EEU, similar to the transit system of the European Union (hereinafter referred to as the EU), developed simultaneously with the unified guarantee system, followed by integration (conjugation) of these two systems with mutual interest.

The development and widespread use of information and communication technologies (ICT) is a global trend of world development and the scientific and technological revolution of the last decades. The use of modern technologies for processing and transmitting information is crucial to both increase the competitiveness of the economy and expand its possibilities for integrating it into the world economic system, and to improve the efficiency of public administration processes at all levels of government in the state and nonstate sectors of the economy [5], [6], [22]. 
- $\quad$ subscription and coding of goods;

The EU implemented a unified system of customs transit of goods, the so-called NCTS (New Computerized Transit System), which accelerated and simplified the movement of goods in mutual and foreign trade with the EU. The Federal Customs Service of Russia needs to develop and introduce a local customs system covering all customs procedures, which is note in the Strategy for the Development of the Customs Service of the Russian Federation until 2020 [19], [20].

The introduction of new information technologies into the activities of customs authorities, primarily to improve customs operations and improve the efficiency of customs control, is one of the main tasks set forth in the Concept of the Information and Technical Policy of the Federal Customs Service of Russia. In the process of implementation of customs information and technical policy is the main source for the implementation of the NTP and is the basis for the development of information technology infrastructure and informatization of customs authorities.

Informational interaction of customs authorities in monitoring transit traffic on the territory of the EEU at this stage is ensure by using national customs transit control software (in the Russian Federal Customs Service - an automated customs transit control system (hereinafter ACTCS-2)) that interact through the common process control subsystem ( hereinafter CPCS), simultaneously operating in the Federal Customs Service of Russia (Central Information and Technical Customs Administration (hereinafter - CITCA)), in the State Customs Committee of the Republic of Belarus (Minsk Central Customs) and the Representative Office of the Customs Service of the Russian Federation at the Customs Service of the Republic of Kazakhstan, as well as the integrate information system of the EEU, functioning in the Eurasian Economic Commission (hereinafter - EEC) to interact with the national transit systems of the Republic of Armenia and the Kyrgyz Republic.

UCTS EEU can significantly simplify the implementation of relevant operations. On the other hand, this system can ensure the coordinated actions of the customs authorities and other executive authorities. That is, it should not only simplify the formalities and increase the efficiency of customs control, but also have managerial (administrative) importance, increasing the efficiency of customs management by the Federal Customs Service of Russia.

\section{UCTS EEU should include:}

- the subsystem of the formation of a data bank, covering information about the genuine, lost, stolen and fake customs seals and seals, completed notifications on the carriage of cargo and guarantee certificates;

- a warning subsystem that allows the transfer of information on the transport of goods, as well as goods with increased risk of smuggling from the customs office of departure to the customs transit points and customs of the destination;
- the subsystem for the formation and transmission of data in the format of a single administrative notice;

- transportation registration subsystem (MRN Movement Reference Number). The one-time MRN number will help accelerate the identification of data on cargo handling at all stages of transportation;

- the subsystem of information interaction of regulatory authorities.

Today, this control system has established itself as the most modern, fast and reliable way to control the movement of goods through the territories of third countries.

When building a UCTS EEU operating with the use of technical means and interfacing information systems of the EAEU Member States, it is necessary to proceed from the following principles:

- The basis for the information interaction of the customs services of the EEU member states in transit of goods should be an exchange of legally relevant electronic documents (mainly in a formalized form). This will optimize the process of customs operations by providing opportunities for deeper automation of the processes of customs declaration and customs control, the possibility of early decision-making within the risk management system and will have a positive impact on the development of the EEU transit potential as a whole;

- The use of information technology with the control of the transit of goods with the use of technological devices operating on the basis of satellite positioning systems (navigation seals) throughout the transportation from the point of entry into the EEU customs territory before unloading them at the recipient's warehouse [7], [14];

- The principle of uniform application of interim measures in transit of goods, providing for the development and application of common approaches, conditions and rules for the application of the provision of financial guarantees;

- The principle of single presentation of documents and information to the customs authority. The implementation of this principle will make it possible to use advance information submitted in the form of an electronic document as an electronic transit declaration for the transport of goods and further at other stages of customs control and customs declaration after the goods arrive at the place of delivery [8], [9];

- The principle of a "unified status model of transit operations" containing a description of business processes, information flows, lists of information to be exchanged between customs services. This principle implies the definition of a "set of rules" involving the use of a single information space, 
Therefore, the task of the Federal Customs Service of common approaches when applying a system of financial guarantees, as well as the possibility of ensuring the "transparency" of goods transit through the EEU territory, including the possibility of monitoring the movement of transit goods EEU members apply special economic measures;

- The need to unify the laws of the EEU member states regarding the prosecution and / or application of measures to carriers and other persons for violations committed during the transportation of goods in accordance with CPTT, including noncompliance with the transportation routes established by customs authorities. This principle has as its goal the exclusion of circumstances in which unscrupulous traders may go unpunished in one EEU member state, having committed an offense related to the transportation of goods throughout the territory of another;

- Implementation of common customs processes in the information interaction of the customs services of the EEU member states, providing for:

- exchange of electronic documents and (or) information in the process of controlling the transit of goods;

- exchange of electronic certificates of collateral and information necessary for the recovery of customs duties and taxes due;

- exchange of information on the use of navigation seals, including their activation / deactivation;

- exchange of advance information submitted in the form of an electronic document;

- interaction in the absence of information about the delivery of goods, or upon receipt of information about their non-delivery.

Common processes are the most important element in the functioning of a unified transit system for goods in the EEU area and allow for a unified approach to customs operations related to the control of goods transit, the principles of such control, prompt identification of violations and taking measures to prevent damage to the budgets of EEU member states [23], [28].

The introduction of computer technology in the customs declaration of goods is an obvious and inevitable process. The reasons for this are the advantages of automated information processing:

- $\quad$ high processing speed;

- $\quad$ an increase in the volume of work performed;

- $\quad$ high reliability;

- the continuity of machine labor generates stability of work, and hence, the acceleration of customs declaration [26], [27].
Russia is to develop a phased transition to a computerized system. The development of unified customs documents will be among the initial stages of such a transition.

The introduction of a computerized system in Russia is necessary for the further development of foreign economic activity and interaction with other states and international organizations (in particular, the EU). Transport facilitation measures should focus on standardization, harmonization and simplification of transit policies, as well as relevant regulations, formalities, procedures and documents, and on organizational matters.

It is necessary to legislate the status of an electronic document and its legal properties for the effective implementation of computerized systems in Russia. The use of electronic communications should be governed by special procedural rules set out in customs legislation. Computerized customs systems should not be limited to links between national and foreign customs authorities. They should be design in such a way that there is an opportunity to interact with other bodies and organizations (for example, to obtain information about paying taxes, finding goods in a wanted list, and whether goods meet sanitary requirements)

To reduce downtime at checkpoints and reduce queues at the border, the Federal Customs Service of Russia needs to implement an information system - GoSwift, which would allow monitoring transit and making adjustments if necessary. This system is already operating in the EU and very successfully. The GoSwift system is suitable for use by the customs service, but requires optimization for work on the territory of the EEU, as well as the creation of technical regulations and standards.

To ensure the traceability of transit cargoes, as well as to minimize the cases of unauthorized opening, it may be advisable to consider the introduction of electronic seals, for example, based on the GLONASS technology. An electronic seal is a locking device and an electronic filling, which stores all the necessary information about the sender, recipient, route, the cargo being transport, etc. An important feature of the electronic seal is that it allows you to track the movement of cargo along a route using GPS.

With the help of electronic seals, it will be possible:

- to visualize with the help of the maps loaded into the system (Yandex, Google) the vehicle's stay with the goods in a specific location;

- track the speed of movement of the vehicle with the goods;

- to visualize the reasons for which the connection with the seal with the designation of the date and time, as well as the corresponding description (loss of communication, opening the seal) was lost; work of the seals for a certain date of time;

- $\quad$ set the time, date, as well as visualize the area in which the seal was installed on the vehicle (wagon).
- to prepare a consolidated report on violations of the 
The technology of electronic sealing will significantly reduce the time of delivery of goods, inspections at customs, improve safety in transport, and introduce electronic document management on international transport. This will help eliminate violations of customs legislation and the human factor during inspections [29], [30].

As the next example of the direction for the further development of the CPCT, the Federal Customs Service of Russia can be propose to support the e-CMR and TIR systems.

The e-CMR system is governed by the Additional Protocol to the Convention on the Contract for the International Carriage of Goods by Road (hereinafter the CMR) relating to the e-CMR electronic consignment note, [15], [21], [25]. The European Commission, represented by the European Commissioner for Transport Violeta Bulk, as well as the united Eurasian Commission of the United Nations Organization, has already supported this system.

The e-CMR system will provide several advantages:

- financial (the total amount of transportation costs is 3-4 times less, faster paperwork (because you need to enter less data, you do not need paper copies of documents, you do not need to fax / scan / send documents by mail, you do not need to store documents in archives, etc.), faster invoicing, as well as fewer discrepancies in shipping and receiving goods) [12], [13], [24];

- $\quad$ transparency of operations and traceability of goods (accuracy of data, monitoring of goods, access to information in real time and the ability to confirm receipt and delivery of goods).

In addition, this system will facilitate cooperation with services that carry out customs declaration, as well as cooperation with other services, in particular, with services that monitor the transport and fleet management [10], [11]. Thanks to the e-CMR system, logistics efficiency is increased (by increasing the economic competitiveness of countries and parties), and road safety is improved (for example, by connecting e-CMR to the e-Call system (automatic emergency call system for freight transport).

\section{CONCLUSION}

The introduction and further development of new information technologies can be successfully implemented only when it is the final stage, which is preceded by a whole set of interrelated activities carried out in a strictly defined sequence. The information system of the customs authorities belongs to the class of large and complex dynamic systems. It consists of a large number of elements that implement the managerial functions of foreign economic activity.

The e-TIR system of the International Road Transport Union (hereinafter referred to as the IRTU) aimed at computerizing the TIR procedure with a further increase in the safety and efficiency of the TIR system. The goal of eTIR is to bring together the advantages offered by existing IT tools and systems, computerized processes in logistics, transportation, e-Customs (e-Customs) and other relevant processes, to make the TIR procedure simpler, interconnected and adapted to the trends of modern customs declaration and logistics [16], [17], [18].

For the Federal Customs Service of Russia, this system will provide the following benefits:

- Reducing the amount of work with documents simplifies and accelerates the implementation of customs control. The possibility of easy integration with universal systems to optimize procedures;

- The IRU and Eurasian Commission of the United Nations Organization systems offer secure web services to customs authorities to verify the validity of a specific electronic guarantee and to receive all e-TIR transport data;

- Customs officers have instant access to the TIR data provided by all previous customs points, including the declaration accepted at the customs point of departure and the number of the seal. The electronic process provides greater security, reducing the risk of fraud.

Participants of foreign economic activity will also have advantages:

- $\quad$ no need to spend time traveling to get paper TIR carnets. The holder receives them on-line on demand and prints (the TIR Carnet printed at home);

- the online payment mechanism allows you to save money and is more environmentally friendly, because when using the Holder, it is not necessary to physically appear in the Association;

- "print at home" TIR carnet is filled automatically before printing by the carrier, which significantly speeds up the procedure and reduces the risk of error;

- "Printed at home" TIR Carnet can be print at any time and remotely, can be send by e-mail in ".pdf" format.

The above proposals will help the Federal Customs Service of Russia, as the responsible body for the regulation of goods CPCT, to solve a number of problems related to the imperfection of the legal framework, information technologies and controls in the area of transit of goods both across the EAEU [31], [32] and through third countries, as well as aimed at unification of regulation and facilitation of transit of goods.

\section{REFERENCES}

[1] A. Caris, C. Macharis, G.K. Janssens, Planning problems in intermodal freight transport: accomplishments and prospects, Transportation Planning and Technology 31 (3) (2008) 277-302.

[2] M. Babin, M. Buda, J. Majercak. Railway Companies and Legislation Scheme in Transportation of Dangerous Goods. 16th International Conference on Transport Means. Kaunas OCT 25-26, 2012. Book Series: Transport Means - Proceedings of the International Conference, 2012. Pp. 37-40. 
[22] Resolution SC.1 for representation of a session of Committee on inland transport in 2017 [An electronic resource]: UNECE. URL: http://www.unece.org/(date of the address: 19.06.2019).

[23] The additional protocol to the Convention on the contract of the international road transportation of goods (KDPG) concerning the electronic consignment note. [Electronic resource]: UNECE. URL: https://www.unece.org/fileadmin/DAM/trans/conventn/e-CMRr.pdf (date of the address: 19.06.2019).

[24] The resolution of the Government of the Russian Federation "About accession of the Russian Federation to the Additional protocol to the Convention on the contract of the international road transportation of goods (KDPG) concerning the electronic consignment note" of 30.01.2018 the No. 83//" Collection of the Legislation of the Russian Federation", 05.02.2018, No. 6, Article 905. [Electronic resource]: Union of Right Forces Consultant Plus. URL http://www.consultant.ru/(date of the address: 19.06.2019).

[25] Thor-Erik Sandberg Hanssen, Terje Andreas Mathisen, Finn Jørgensen. Generalized transport costs in intermodal freight transport Procedia - Social and Behavioral Sciences 54. 2012. 189 - 200. doi: 10.1016/j.sbspro.2012.09.738

[26] O. Pokrovskaya. Terminalistics as the methodology of integrated assessment of transportation and warehousing systems/ O Pokrovskaya // MATEC Web of Conferences. Volume 216 (2018) X International Scientific and Technical Conference "Polytransport Systems". - Tomsk, Russia, November 15-16, 2018. A.D. Abramov A.L. Manakov, A.A. Klimov, V.I. Khabarov and V.I. Medvedev (Eds.). DOI: https://doi.org/10.1051/matecconf/201821602014

[27] D. Morkovkin, S. Shmanev, L. Shmaneva. Problems and trends of innovative transformation of the Russian economy and infrastructure development // proceedings of the 3rd International conference on Economics, management, law and education (EMLE 2017) / AEBMR-achievements in the field of business Economics and management. 2017. Vol. 32. p. 10-13.

[28] R. Lv, C. Li. Analysis on location selection of dry ports based on ANP, 16th International Conference on Industrial Engineering and Engineering Management, IEEE, 2009.

[29] T. Notteboom, J.-P. Rodrigue, Inland terminals within North American and European supply chains, Transport and Communications Bulletin for Asia and the Pacific 78. 2009. pp. 1-39.

[30] Yunfei Wang, Ioana C. Bilegan, Teodor Gabriel Crainic, Abdelhakim Artiba. Transportation Research Procedia 3, 2-4 July, 2014, p. 621 630. doi: 10.1016/j.trpro.2014.10.041

[31] T.V. Malysheva, A.I. Shinkevich, E.V. Zelenkina, I.S. Denisov, T.M Vorotyntseva, O.A. Dmitrieva, V.I. Kurdyumov. Development and concentration efficiency study of enterprises innovation activity in real sector of economy // Eurasian Journal of Analytical Chemistry. 2017. T. 12. № 7. pp. 1347-1356.

[32] V.A. Shumaev, A.A. Odintsov, A.A. Sazonov. V.V. Raniuk, N.I Arkhipova and D.E. Morkovkin. Model of efficient cost reduction instrument for machine construction // Modern journal of language teaching methods. 2018. T.8. № 3. pp. 279-289.

[18] M. J. Meixwell \& M. Norbis. A review of the transportation mode choice and carrier selection litterature. International journal of Logistics Management, (2008), 19 (2), pp. 183-211.

[19] Order of the Government of the Russian Federation "About the Development strategy of customs service of the Russian Federation till 2020" of 28.12.2012 No. 2575-r//"Collection of the legislation of the Russian Federation", 14.01.2013, No. 2, Article 109. [Electronic resource]: Union of Right Forces Consultant Plus. URL: http://www.consultant.ru/(date of the address: 19.06.2019).

[20] Official site of "IRU". [Electronic resource]: IRU. URL: https://www.iru.org (date of the address: 19.06.2019).

[21] O. D. Pokrovskaya. Study Of The Typology Of Logistic Entities Using Functional And Logistic Approach / O. Pokrovskaya, R. Fedorenko, E. Khramtsova // GCPMED 2018 - International Scientific Conference "Global Challenges and Prospects of the Modern Economic Development". - Vol. LVII. - 06 - 08 December 2018, Samara, Russia / The European Proceedings of Social \& Behavioural Sciences EpSBS.- No: 10. P. 91-101. DOI: https://dx.doi.org/10.15405/epsbs.2019.03.10 